\title{
IDENTIDADE E PROFISSIONALISMO DOCENTE: UMA REVISÃO DA ABORDAGEM NARRATIVA
}

\section{RAQUEL SOFIA DOS SANTOS MACEDO MATOS}

Instituto de Educação da Universidade do Minho

RESUMO

Este estudo insere-se num projeto de investigação sobre o desenvolvimento do sentido de identidade e do profissionalismo dos professores no curso das suas vidas. Em forma de estado da arte, propõe analisar de que formas a investigação (auto)biográfica tem contribuído para a construção de conhecimento sobre as questões da identidade e do profissionalismo docente. Nesse sentido, apresentase como uma síntese dos trabalhos de natureza empírica realizados sobre estas temáticas, e metodologicamente ancorados na pesquisa biográfica, entre 2005 e 2015, no Brasil e em Portugal. A recolha de dados foi realizada a partir de bases de dados de repositórios científicos dos dois países (OASIS; RCAAP; SCIELO), utilizando como conceitos-chave identidade profissional; narrativas biográficas; histórias de vida e profissionalismo docente. Definimos como critério de seleção dos artigos a publicação em revistas da área da Educação com revisão de pares. Selecionamos e analisamos 17 artigos e 12 teses de doutoramento. Os resultados do estudo manifestam a produtividade das pesquisas (auto)biográficas, quer numa perspetiva de pesquisa quer como práticas de formação. Encontramos e mapeamos uma grande diversidade de referenciais teóricos, de apropriações e aproximações à pesquisa (auto)biográfica, nos investigadores de ambos os países. Encontramos no universo brasileiro um maior número de investigações de caráter interventivo, com o uso de estratégias metodológicas apostadas na construção da identidade dos sujeitos - professores e nas investigações de pesquisa-formação.

Palavras-chave: Profissionalismo docente. Narrativas. Identidade profissional.

\section{ABSTRACT TEACHER IDENTITY AND PROFESSIONALISM: AN}

\section{(AUTO)BIOGRAPHICAL RESEARCH APPROACH REVIEW}

This research is part of an investigation project about the sense of teachers' identity and professionalism throughout their lives. Encompassing the latest developments in this area, the main purpose of this study is to analyse the ways in which (auto)biographical re- 
search has contributed to the increase of knowledge on teachers' identity and professionalism. In that sense, this is a review of the empirical researches based on autobiographical methods, regarding these issues, between 2005 and 2015, both in Portugal and Brazil. Data collection was carried out from databases of open Access Scientific Repositories from both countries (OASIS; RCAAP; SCIELO), using the following keywords: professional identity; biographical narratives,; life histories and teachers professionalism. All articles were selected on peer reviewed educational journals. We have selected and analysed 17 articles and 12 doctoral theses. The analysis demonstrates that (auto)biographical research is being successfully used both as a method and as a training practice. We have found and mapped a great diversity of theoretical approaches and ways of using the (auto) biographical research method by the researchers of both countries. Keywords: Teachers' professionalism. Narratives. Professional identity.

\section{RESUMEN IDENTIDAD Y PROFESIONALIDAD DOCENTE:}

\section{CONTRIBUICIÓN DE LA INVESTIGACIÓN NARRATIVA}

Esta investigación es parte de un proyecto sobre el sentido de identidad e de profesionalismo de los profesores a lo largo de sus vidas. Con este estado del arte, nos proponemos analizar los aportes de la investigación (auto)biográfica en la construcción de conocimiento sobre la identidad y el profesionalismo docente. Presentaremos una síntesis de las investigaciones con datos empíricos sobre estos temas donde se han utilizado metodologías auto(biográficas), entre 2005 y 2015, en Portugal y Brasil. Los datos se han recogido en las bases de datos de repositorios científicos de los dos países (OASIS; RCAAP; SCIELO) buscando las palabras-clave identidad profesional; narrativas biográficas; historias de vida y profesionalismo docente. Los artículos seleccionados se encuentran publicados con revisión de pares en periódicos de educación. Se han seleccionado 17 artículos de periódico y 17 tesis de doctorado. Los resultados de investigación demuestran la productividad de la investigación (auto)biográfica como metodología de investigación y como practica de formación. Se ha encontrado e mapeado una gran diversidad de referenciales teóricos e de diferentes acercamientos a la investigación auto(biográfica) en los investigadores de los dos países.

Palabras clave: Profesionalismo docente. Narrativas. Identidad profesional. 


\section{Introdução}

A profissão docente tem sido objeto de um intenso e renovado interesse dos investigadores em educação desde os anos 90 do século XX. Desde então, têm vindo a desenvolver-se estudos de natureza multidisciplinar que visam compreender o(s) sentido(s) do ser professor. Esse interesse acompanhou, e em parte foi motivado pela tão falada crise na educação, que levou a novos questionamentos sobre o papel dos professores como atores principais da desejada mudança educativa (XAVIER, 2014).

Sabemos hoje que pensar a profissão docente passa por reconhecer, desde logo, o carácter pessoal do ato de ensinar, admitindo "que não é possivel separar o eu pessoal do eu profissional, sobretudo numa profissão fortemente impregnada de valores e de ideias e muito exigente do ponto de vista do empenhamento e da relação humana" (NÓVOA, 1992, p. 9).

Partindo desse pressuposto, do ponto de vista metodológico, assistiu-se durante este tempo à aceitação e utilização progressivas das abordagens (auto)biográficas na pesquisa em educação, reconhecendo o potencial das histórias de vida para aprofundar o conhecimento sobre os professores.

0 presente trabalho insere-se nesse movimento e assume essa filiação. Faz parte de um projeto de investigação sobre o desenvolvimento do sentido de identidade e do profissionalismo dos professores no curso das suas vidas e tem como objetivo analisar de que formas a investigação (auto)biográfica tem contribuído para a construção de conhecimento sobre as questões da identidade e do profissionalismo docente.

Começaremos por abordar os conceitos de profissionalismo e identidade docente, recorrendo a referenciais teóricos que consideram a dimensão biográfica de ambos. Faremos, de- pois, uma breve descrição dos diferentes tipos de pesquisa, marcados por objetivos diferentes e por diferentes apropriações do método (auto)biográfico.

0 presente estudo tem a forma de estado da arte, apresentando-se como uma sintese dos trabalhos de natureza empírica realizados sobre estas temáticas, e metodologicamente ancorados na pesquisa biográfica, entre 2005 e 2015, no Brasil e em Portugal. Passaremos então à apresentação dos dados recolhidos e à posterior (re)formulação do problema e dos objetivos de investigação considerando este estado da arte.

\section{Profissionalismo docente, identidade e (auto)biografia}

Nos últimos anos, as políticas educativas e curriculares fizeram surgir aquilo que Hargreaves e Fink (2007, p. 21) classificaram de "movimento da reforma educativa e dos padrões de desempenho [standards]" que, nas palavras dos dois autores, "exprime a noção de que a aprendizagem tem prioridade sobre o ensino e que deveríamos ser capazes de saber e de demonstrar quando é que essa aprendizagem ocorre efetivamente". Estão determinados os conteúdos que os professores devem trabalhar e o que os alunos devem aprender, escrutinando a posteriori, por via da avaliação externa, os resultados em relação às finalidades preestabelecidas. No que respeita ao exercício da docência, esta é uma nova forma da tutela (re)centralizar os poderes de decisão educativa e curricular (MORGADO, 2014). Além disso, as políticas que norteiam estas reformas têm feito da avaliação do desempenho um dos seus eixos estruturantes, e esta tem sido usada menos ao serviço do desenvolvimento positivo do profissionalismo docente, e mais como um mecanismo de pressão sobre os professores, responsabilizando -os pelos resultados do sistema. 
Vários autores (DAY, 2004; KELCHTERMAN 2009; OSBORN, 2006; PACHECO, 2008) têm alertado que estas propostas assentes na performatividade, reproduzidas em muitos paises, entre os quais Portugal e em certa medida o Brasil, encerram uma conceção reducionista da educação, na medida em que reduzem e alteram o que conta como ensino e qualidade das aprendizagens e o que significa ser professor.

A desvalorização da dimensão afetiva do ensino - nomeadamente o sentido de vocação e o investimento na individualidade da pessoa - condicionada à pressão do desempenho em termos de resultados escolares, numa visão de professor enquanto técnico que deve transmitir conteúdos, faz com que que os contextos de ensino se configurem como "produtores de identidades técnicas" (PACHECO, 2009, p. 117). Apesar de todos estes constrangimentos, é a forma como os professores se posicionam e exercem a profissão dentro destas políticas que configura uma parte importante do seu profissionalismo.

O profissionalismo docente é um conceito complexo e dinâmico que comporta "uma dimensão coletiva, que é parte integrante de uma profissão, e uma dimensão individual ligada à maneira como cada docente se prepara e coloca face a ela, a pratica, partilha da cultura do grupo e constrói a sua identidade profissional" (ESTRELA, 2014, p. 11). A aproximação ao profissionalismo docente passa, portanto, necessariamente pelo entendimento do processo de profissionalização dos professores e da história da profissão (NÓVOA, 1992), pela compreensão das políticas curriculares correspondentes ao tempo e espaço onde é exercido esse profissionalismo e pelo(s) sentido(s) de identidade construído(s) ao longo desse processo, encarnados nas vidas concretas de cada professor.

Vai nesse sentido a teoria de Claude Dubar (2005), segundo a qual as identidades profis- sionais resultam de dois processos identitários que se articulam. Um diz respeito a uma identidade atribuída (pelas instituições, pelos pares), onde são forjadas as categorias utilizadas para identificar um indivíduo num dado espaço social, e a que Dubar chamou de "identidade estrutural" ou "identidade para outrem" (DUBAR, 2005). o outro é a "(re)construção subjetiva de uma definição de si" que designou de "identidade biográfica". Segundo o autor, o processo identitário individual é, geralmente, apreendido a partir de produções de linguagem do tipo "biográfico" e diz respeito às diversas maneiras pelas quais indivíduos tentam dar conta de suas trajetórias (familiares, escolares, profissionais...) por meio de uma "história" (DUBAR, 2005).

Também para Nóvoa (2013) é mais acertado falar em processo identitário, através do qual cada um se apropria do sentido da sua história pessoal e profissional. É um processo que passa também pelo exercício da autonomia e que se faz no tempo, nas decisões tomadas diariamente, as quais, para nós professores, "cruzam a nossa maneira de ser com a nossa maneira de ensinar e desvendam na nossa maneira de ensinar a nossa maneira de ser" (NÓVOA, 2013, p. 9).

Preocupado com as questões do currículo e com o exercício da profissão docente, Ivor Goodson (2008, p. 17), compreende que "devemos entender o pessoal e o biográfico se quisermos entender o social e o político", pois a atuação dos professores no contexto escolar está diretamente ligadas às suas experiências. Num contexto de crise e de desejo de mudança na educação, Goodson defende o potencial do professor como agente de mudança positiva, sendo necessário para tal "dar destaque à sua biografia pessoal - às missões e entregas pessoais que subjazem aos seus sentidos de vocação e de zelo pela sua profissão" (GOODSON, 2015, p. 63) e, ao mesmo tempo, promo- 
ver processos reflexivos que incidam sobre o desenvolvimento pessoal e profissional dos professores, dando-lhes voz e colocando-os no centro desse alargamento do seu próprio sentido de identidade profissional.

Dentro deste quadro teórico sobre a identidade e o profissionalismo docente, vamos encontrar uma preferência metodológica pelas investigações de cariz (auto)biográfico.

Epistemologicamente, a pesquisa (auto) biográfica enquadra-se no paradigma qualitativo que "pretende substituir as noções de explicação, previsão e controlo do paradigma quantitativo pelas de compreensão, significado e ação em que se procura penetrar no mundo pessoal dos sujeitos" (COUTINHO, 2008, p. 7). É este olhar em profundidade que autoriza a pesquisa (auto)biográfica a explorar a complexa realidade educativa. Aproximando-se dos atores educativos, entre os quais os professores desempenham um dos papéis principais, faz emergir sentidos das suas experiências de vida, pessoais e sociais.

Os estudos das histórias de vida no campo educacional centram-se na pessoa do professor, com ênfase nas subjetividades e identidades que as histórias comportam. Com a centralização dos estudos e práticas de formação na pessoa do professor, busca-se abordar a constituição do trabalho docente levando-se em conta os diferentes aspetos de sua história: pessoal, profissional e organizacional. (SOUZA, 2006, p. 69)

O comentário de Souza faz sobressair o carácter heurístico dos estudos das histórias de vida. António Nóvoa (2013) deu conta da grande produtividade e da diversidade de abordagens das investigações (auto)biográficas. Se é certo que a profusão de abordagens e perspetivas usadas nas investigações com histórias de vida merece vigilância metodológica por parte dos investigadores, não é menos verdade que a sua qualidade heurística resulta da "possibilidade de conjugar diversos olhares disciplinares, de construir uma compreensão multifacetada e de produzir um conhecimento que se situa na encruzilhada de vários saberes" (NÓVOA, 2013, p. 20).

Bueno (2006) e um grupo de investigadores da Universidade de São Paulo realizaram uma revisão de trabalhos da área de Educação que fizeram uso das histórias de vida e dos estudos autobiográficos como metodologia de investigação científica no Brasil, entre 1985 e 2003, sobre formação de professores e a profissão docente. A análise do material reunido a partir de 1990 foi "reveladora de um visivel crescimento das pesquisas nesse período, mas também de uma significativa diversificação das modalidades e dos usos das autobiografias e histórias de vida" (BUENO et al., 2006, p. 9). Os resultados do estudo mostram o interesse por temáticas até então novas, tais como a profissionalização e a identidade docente, esta última motivando o maior número de pesquisas. À data do estudo, porém, os investigadores mostravam-se surpreendidos por ver que a perspetiva da pesquisa/formação proposta por alguns teóricos europeus, e defendida pelos investigadores brasileiros, não tinha chegado a ser utilizada em muitos estudos empíricos, prevalecendo a perspetiva das histórias de vida ao "serviço de projetos", para usar o conceito de Christine Josso (1999). A análise dos dados chama a atenção para a imprecisão concetual nos estudos realizados e os investigadores deixam como recomendação o aprofundamento sobre esses aspetos, notadamente sobre as apropriações concetuais e uma definição mais precisa dos referenciais teóricos e procedimentos de pesquisa e de formação pertinentes ao campo das autobiografias e histórias de vida.

O trabalho que aqui apresentamos propõe, dentro das limitações que apresentaremos, continuar a referida revisão, apresentandose como uma sintese dos trabalhos de natu- 
reza empírica realizados sobre a identidade e o profissionalismo docente, e metodologicamente ancorados na pesquisa biográfica, entre 2005 e 2015, no Brasil e em Portugal.

\section{Metodologia}

O estudo segue a metodologia própria dos estudos chamados de estado da arte. A recolha de dados, centrada na análise documental, foi realizada a partir de bases de dados de repositórios científicos dos dois países (OASIS; RCAAP; SCIELO), utilizando como descritores de busca nos resumos: identidade profissional; profissionalismo e combinando cada um deles com professores e narrativas biográficas ou histórias de vida. 0 corpus de análise tem como cri- tério de seleção teses de doutoramento e artigos publicados em revistas da área da Educação com revisão de pares. Procedemos então à análise dos resumos, despistando faltas de correspondência entre as palavras-chave dos resumos e os descritores que selecionamos e desvios temáticos evidentes nos resumos. Depois dessa primeira análise, selecionamos e analisamos um total de 17 artigos e 12 teses de doutoramento, nos dois países, que respondiam aos critérios previamente definidos.

Depois de selecionados, começamos por fazer uma análise da distribuição temporal dos estudos, procurando marcar, para comparar, a quantidade de estudos realizados num e no outro país.

Quadro 1 - Matriz de categorização dos estudos das histórias de vida (Nóvoa, 2013)

\begin{tabular}{|l|c|c|c|}
\hline Objetivos & $\begin{array}{l}\text { Objetivos essencialmente } \\
\text { teóricos, relacionados com } \\
\text { a investigação }\end{array}$ & $\begin{array}{l}\text { Objetivos essencialmente } \\
\text { práticos, relacionados com } \\
\text { a formação }\end{array}$ & $\begin{array}{l}\text { Objetivos essencialmente } \\
\text { emancipatórios, relacionados } \\
\text { com a investigação-formação }\end{array}$ \\
\hline Dimensões \\
\hline $\begin{array}{l}\text { Pessoa } \\
\text { (do professor) }\end{array}$ & 1 & 4 & 7 \\
\hline $\begin{array}{l}\text { Práticas } \\
\text { (do professor) }\end{array}$ & 2 & 5 & 9 \\
\hline $\begin{array}{l}\text { Profissão } \\
\text { (do professor) }\end{array}$ & 3 & 6 & 9 \\
\hline
\end{tabular}

Tentamos então proceder a uma categorização dos dados, no entanto, tendo em conta a diversidade encontrada, as diferentes abordagens das histórias de vida dos professores e a interdependência temática das questões da identidade e do profissionalismo docente, sentimos a dificuldade já notada por António Nóvoa: "é muito difícil separar analiticamente as distintas abordagens (auto)biográficas, na mediada em que elas se caracterizam justamente por um esforço de globalização e de integração de diferentes perspetivas" (NÓVOA, 2013, p. 20). O investigador português propõe uma matriz (Quadro 1) de categoriza- ção "baseada nos objetivos e nas dimensões que cada uma das abordagens privilegia" (NÓVOA, 2013, p. 20), agrupando nove tipos de estudos.

No nosso caso, porque tratando-se das temáticas da identidade e do profissionalismo docente nas quais as dimensões pessoa-práticas-profissão estão intrinsecamente relacionadas, como podemos ver pelos quadros teóricos apresentados na segunda parte desta comunicação, optámos por fazer uma categorização dos estudos centrada nos objetivos da investigação, mas seguindo aí a formulação de Nóvoa (2013), como adiante se verá. 


\section{Descrição dos dados}

Dos 29 estudos analisados, sete foram desenvolvidos e publicados em Portugal, 21 no Brasil e um artigo resultou da investigação conjunta de duas pesquisadoras do Instituto de Educação da Universidade de Lisboa e da Universidade Estadual de Londrina (OLIVEIRA; CYRINO, 2011).

Das 12 teses de doutoramento analisadas, sete são projetos de investigação de universida- des brasileiras, sendo que três foram desenvolvidos na Pontificia Universidade Católica do Rio Grande do Sul e duas na Faculdade de Educação da Universidade Federal do Ceará, mostrando a vitalidade dos estudos sobre vidas de professores nos cursos de pós-graduação nestas instituições. No caso de Portugal, das seis teses estudadas, destaca-se, com duas teses, o Instituto de Educação da Universidade do Minho.

Gráfico 1 - Estudos com histórias de vida sobre identidade e profissionalismo docente

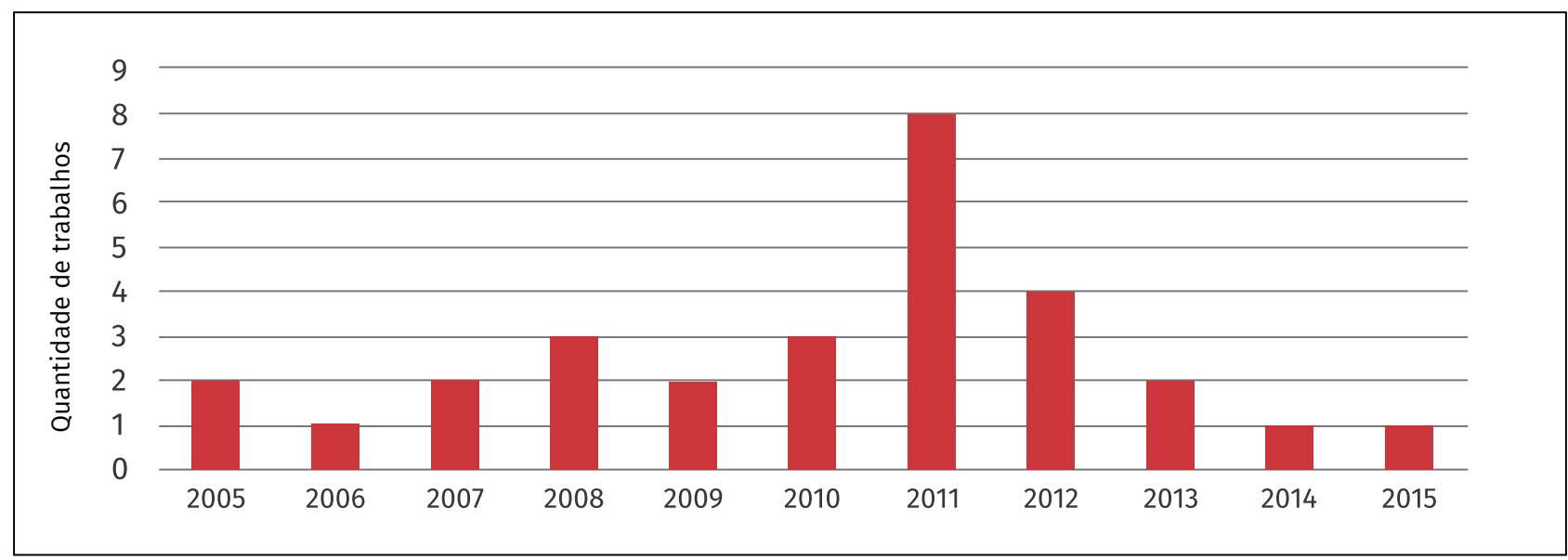

Fonte: Elaborado pela autora

0 recorte temporal, que apresentamos no gráfico1, mostra a existência de pelo menos um estudo publicado em cada um dos anos, destacando-se o ano de 2011, durante o qual foram publicados oito estudos, cinco no Brasil e trêsem Portugal, coincidente com a publicação do primeiro número de 2011 da revista Educação em
Revista, que contém um dossiê dedicado à exploração das relações entre a expressão biográfica e a educação.

No quadro 2, a seguir, apresentamos a distribuição dos trabalhos dos dois países, categorizados de acordo com os objetivos da investigação, segundo a matriz apresentada por Nóvoa (2013).

Quadro 2 - Matriz de categorização - objetivos de investigação

\begin{tabular}{|c|c|c|c|}
\cline { 2 - 4 } \multicolumn{1}{c|}{} & $\begin{array}{l}\text { Objetivos essencialmente } \\
\text { teóricos, relacionados com } \\
\text { a investigação }\end{array}$ & $\begin{array}{l}\text { Objetivos essencialmente } \\
\text { práticos, relacionados com } \\
\text { a formação }\end{array}$ & $\begin{array}{l}\text { Objetivos essencialmente } \\
\text { emancipatórios, relacionados } \\
\text { com a investigação-formação }\end{array}$ \\
\hline Portugal & 8 & 1 & 1 \\
\hline Brasil & 14 & 3 & 2 \\
\hline Total & 22 & 4 & 3 \\
\hline
\end{tabular}

Fonte: Elaborado pela autora 
A análise dos objetivos de pesquisa confirma, tal como tinham notado Bueno et al. (2006) na sua revisão, que se mantém uma preferência pelo uso de metodologia narrativa em estudos com objetivos de investigação essencialmente teóricos, constituindo 22 das 29 investigações analisadas. Entre esses estudos, prevalece o interesse por aprofundar a construção dos processos identitários dos professores, as relações entre as fases ou etapas das vidas pessoais dos professores e os ciclos de vida profissionais dos docentes [nestes casos, seguindo o referencial teórico de Michaël Huberman (1989)]. No entanto, ainda que em menor número, é significativo encontrar pesquisas que revelam marcadas preocupações com as questões do currículo e da relação entre as vidas dos professores, os seus saberes e as suas práticas curriculares. Assinalamos a tese de doutoramento de Gilson Pereira (2007), da Pontifícia Universidade Católica do Rio Grande do Sul, sob o título No fio da história: uma análise da (re)construção identitária dos professores: entrecruzando tempos, memórias e espaços, voltada para as "tramas" que levaram às escolhas pessoais e profissionais dos professores e mostrando que essas escolhas se refletem diretamente em sua atuação docente, como sujeitos inseridos no contexto escolar. Na mesma universidade, sob orientação de Maria Helena Menna Barreto Abrahão, era apresentada por Maria Bernardete Kroeff (2010) a tese Histórias de vida: trajetórias de professoras no cenário político de Porto Alegre - perfis (auto)biográficos no mundo contemporâneo, resultado de uma pesquisa que procura compreender, através da trajetória de vida de duas professoras que viriam a assumir cargos de deputadas na Assembleia Legislativa do Estado do Rio Grande do Sul, no período de 1990 a 2002, de que forma o seu desenvolvimento profissional contribuiu para que atuassem no poder decisório do Parlamento, em defesa da qualidade do ensino público e do magistério. $\mathrm{Na}$ Universidade de São Carlos, Ester Almeida Helmer (2012) apresentava a tese $O$ processo de construção da profissionalidade docente no Instituto Federal de Educação, Ciência e Tecnologia de São Paulo, cuja investigação se alicerça nas histórias de vida de professores daquele instituto, estudando aspetos da profissionalidade docente compreendida como um processo dinâmico que convoca modos de atuar, destrezas, conhecimentos, atitudes e valores que constituem saberes específicos do ser professor. Em Portugal, no Instituto de Educação da Universidade do Minho, Rosalina Herdeiro (2012) apresentou a tese de doutoramento Identidade(s), carreira e desenvolvimento profissional: um estudo junto de professores do 1을 $C E B$, estudo no qual se propôs questionar os efeitos do Estatuto da Carreira Docente e a Avaliação do Desempenho Docente - na(s) identidade(s), na carreira e no desenvolvimento profissional dos professores, concretamente do 10 CEB. A investigação foi feita através de um estudo longitudinal, realizado entre 2008 e 2010, com recurso a narrativas biográficas escritas e orais. Os resultados da investigação, apontam para "a interferência das políticas educativas e curriculares no trabalho dos professores, condicionando a motivação e a colaboração profissionais e as relações interpessoais em contexto educativo, com repercussões no sucesso dos alunos" (HERDEIRO, 2012, p. 8). Em 2013, na Universidade do Porto, Luciana Matiz, apresentou a sua tese de doutoramento $A$ construção de identidades de professores do 3o CEB e do ensino secundário num contexto de mudança: um estudo narrativo com diferentes gerações de professores. A investigação analisou a construção e a reconstrução da identidade das diferentes gerações de professores do 3으 CEB e do ensino secundário, no atual contexto de mudança educativa. Os resultados do estudo deixam ver 
que existem características que são próprias de cada geração de professores, mas que, na qualidade de profissionais, "os professores das diferentes gerações se assemelham mais do que se distinguem, sendo por isso visivel um núcleo de identidade docente consistente, que a própria crise torna mais explícito" (MATIZ, 2013, p. 5).

Também em menor número, identificamos pesquisas cujos objetivos principais passam pelo uso das narrativas como estratégia de reflexão autoformadora, fazendo memória das práticas dos professores, no sentido de agir sobre os seus projetos de desenvolvimento profissional. É exemplo disso a pesquisa de pósgraduação de que motivou o artigo Memória e (re)criação na formação de professores: trilhando caminhos (CINTRA; ALBANO, 2010), publicado nos Cadernos Cedes, onde as investigadoras abordam uma prática de formação, realizada com alunas do curso de Pedagogia da Universidade Estadual de Campinas (UNI(AMP). Durante a formação, as alunas eram convidadas a reconstruir memórias da escola, de infância e de adolescência e, a partir delas, criar narrativas cénicas, na perspetiva de que se estabelecessem relações entre umas e outras, contribuindo assim para a pesquisa e as práticas de formação docente. Em 2012, na tese Processos identitários docentes: percursos de vida e de trabalho no contexto do Proeja do Instituto Federal de Educação, Ciência e Tecnologia do Ceará, Natal Lânia Roque Fernandes, analisa processos identitários docentes de professores que lecionam no Programa Nacional de Integração da Educação Profissional com a Educação Básica, na Modalidade de Educação de Jovens e Adultos - PROEJA, do Instituto Federal de Educação, Ciência e Tecnologia do Ceará, campus Fortaleza. O estudo evidenciou a importância do uso de narrativas (auto)biográficas como dispositivo para conhecer processos identitários. Segundo a in- vestigadora, a "articulação entre os processos de formação profissional, as experiências de vida e o exercício profissional revelou elementos significativos para pensar a constituição da docência em EJA dos professores participantes da pesquisa" (FERNANDES, 2012, p. 155). Em Portugal, Maria Leonor Terremoto apresentou, na Universidade de Lisboa, em 2012 a tese Da prática à praxis: os saberes experienciais dos professores na construção do ser professor do 1 o ciclo do ensino básico, uma investigação que propôs contribuir para compreender o contributo dos saberes experienciais na construção do professor, especificamente em profissionais do 1.o ciclo do ensino básico, e como esses saberes se consubstanciam num conhecimento praxeológico sobre o ensinar. Através de um estudo de caso múltiplo, incidindo sobre seis professoras do 1.o ciclo do ensino básico, recorrendo a entrevistas de estimulação da memória. Os resultados da investigação revelam "a necessidade e relevância de conceber e desenvolver programas de formação que valorizem a prática como centro da ação formativa, em contextos colaborativos propiciadores de trabalho reflexivo e crítico sobre as práticas, de modo a estimular a construção de saberes profissionais praxeológicos" (TERREMOTO, 2012, p. 3). Também em Memoriais escolares e processos de iniciação à docência (BERGAMASCHI; ALMEIDA, 2013), publicado na revista Educação em Revista, é apresentada uma investigação sobre as narrativas de memória de 14 estudantes do curso de Pedagogia, bolsistas do Programa Institucional de Bolsas de Iniciação à Docência - PIBID. As investigadoras analisaram os memoriais tomando-os como parte importante no processo formativo dos bolsistas que integram o programa.

Seguindo as categorias propostas por Nóvoa (2013), podemos agrupar um conjunto de pesquisas relacionadas com investigação-formação, com objetivos essencialmente emanci- 
patórios, em que os professores são chamados a desempenhar, ao mesmo tempo, o papel de "objetos" e "sujeitos" da investigação, como as biografias educativas (DOMICIÉ, 1990; JOSSO, 1991), quer sejam vocacionados para a transformação das práticas, quer no sentido de transformação da própria profissão docente. Em qualquer dos casos, no movimento de dar voz aos professores, ocorre um processo de empoderamento pessoal e profissional.

Bueno et al. (2006) notavam, com surpresa, que à data da sua análise houvesse poucos estudos empíricos dessa natureza. Neste estudo, identificamos duas teses e um artigo onde as narrativas surgem como projetos de investigação-formação.

Em 2008, Ana Sofia Reis de Castro e Pinho, apresentou, na Universidade de Aveiro, Portugal, a tese Intercompreensão, identidade e conhecimento profissional na formação de professores de línguas. O estudo procurou compreender e descrever atitudes, comportamentos, representações e conhecimentos de um grupo de futuros professores de línguas em situação de Prática Pedagógica, em relação às línguas e culturas e aos processos de ensino e aprendizagem em línguas. Ao nível da intervenção, o estudo apresentou objetivos do foro investigativo e formativo, encontrando-se estruturado num programa de formação, organizado em sessões de formação e no desenvolvimento de projeto de investigação-ação, pelas professoras estagiárias, onde conceberam, implementaram e avaliaram atividades em torno da temática da intercompreensão em línguas. A tese Pesquisa-formação: a construção de si na escuta do outro, apresentada em 2009 por Cristhianny Bento Barreiro, sob orientação de Maria Helena Menna Barreto Abrahão, na Pontifícia Universidade Católica do Rio Grande do Sul, expõe conhecimentos elaborados a partir de uma pesquisa-formação baseada na cons- trução de biografias educativas. Os resultados do projeto deixam ver que "as diferentes experiências formais e informais pertencem a nossa formação enquanto professores e professoras, pessoas singulares que buscam no encontro com a cultura e com a ciência a definição de papéis sociais pré-determinados que, no entanto, serão exercidos com os matizes de cada um"; destacam, ainda, o papel formativo da escuta que resulta da partilha das narrativas; e realçam a importância de se trabalhar na formação de professores com os modelos pedagógicos construídos ao longo da vida.

Encontramos e selecionamos para análise o artigo Entre a vida e a formação: pesquisa (auto)biográfica, docência e profissionalização (PASSEGGI; SOUZA; VICENTINI, 2011). Embora, no artigo, os autores não apresentem um estudo empírico particular, pareceu-nos essencial incluir nesta síntese o projeto "Pesquisa (auto) biográfica: docência, formação e profissionalização", desenvolvido por pesquisadores da Universidade do Estado da Bahia, da Universidade Federal do Rio Grande do Norte e da Universidade de São Paulo, pela vitalidade das investigações do grupo, que toma as narrativas autobiográficas como prática de formação docente e como método de pesquisa. Os autores reconhecem que "as pesquisas no contexto da formação vêm demonstrando duas dimensões importantes para o processo de emancipação do sujeito-ator-autor, por um lado, a reflexividade autobiográfica na promoção da transformação das representações de si, por outro, a possibilidade de 'inserção negociada' na cultura" (PASSEGGI; SOUZA; VICENTINI, 2011, p. 308).

\section{Formulação de um problema e de objetivos de investigação}

A recolha de dados foi feita no âmbito de uma investigação com a qual nos propomos contri- 
buir para um conhecimento mais aprofundado sobre o desenvolvimento do sentido de identidade e do profissionalismo dos professores no curso das suas vidas, entendendo a importância do papel dos professores como construtores do currículo.

Os resultados da análise dos artigos e das teses selecionados reforçaram algumas das nossas questões de partida e abriram espaço a novos questionamentos.

Começamos por questionar as relações que se estabelecem entre os percursos de vida dos professores e a forma como vão compreendendo e exercendo o seu profissionalismo, ao longo do tempo de carreira.

$\mathrm{Na}$ polifonia das vozes dos professores ouvidos, reconhece-se a complexidade da profissão docente, que convoca diferentes dimensões dos sujeitos professores: os seus saberes e afetos, as suas experiências e convicções, o seu sentido ético e de compromisso social.

As investigações analisadas confirmam que, no exercício da profissão docente, a vida afeta as práticas. As práticas profissionais "recebem influências de todo o percurso de vida pessoal e profissional de professores, conforme ficou explicitado nas narrativas de vida das professoras Maria Augusta e Iara" (KROEFF, 2010, p. 144). Os resultados corroboram "o reconhecimento da existência de saberes profissionais pessoais construídos pelos docentes e a relevância do saber experiencial no conhecimento profissional" (TERREMOTO, 2012, p. 425). A relação entre a vida e as práticas dos professores carece, pois, de um maior esforço de reflexão dos investigadores em educação e constitui um repto, muito concreto, aos programas de formação de professores.

Os estudos das histórias de vida confirmam, também, o que muitos autores (DAY, 2004; HARGREAVES, 2000 NÓVOA, 2013) têm apelidado de "paradoxo" e "conflito", e que exprime uma das grandes inquietações que acompanha as vidas dos professores, que é o desfasamento entre as altas expectativas colocadas sobre eles - como atores principais de uma educação democrática, ao serviço do desenvolvimento individual e coletivo - e entre as condições reais - com variados constrangimentos à autonomia pessoal - em que desempenham esse papel. O que nos leva, enquanto investigadores, a questionar que relação existe entre as imagens emergentes da legislação sobre os professores e a forma como os professores se veem a si mesmos.

As investigações dão conta, também, da emergência de novas retóricas sociais e de políticas educativas que desafiam o sentido de identidade profissional dos professores. Nos relatos dos professores atualmente em exercício, percebe-se a intensificação e a burocratização do trabalho docente e a degradação da condição docente e da imagem social dos professores; ao mesmo tempo, vê-se o reforço das suas motivações - a relação com a comunidade local, a sala de aula como espaço de autonomia e realização profissional - mostrando a tensão entre o desânimo e a resiliência dos professores.

Tendo em conta estes dados, parece-nos importante analisar as continuidades e ruturas no sentido de identidade dos professores nos contextos profissionais; analisar a forma como percecionam a mudança e perceber as fontes e estratégias de resiliência dos professores em situações diversas de contextos profissionais.

Acreditamos que o conhecimento sobre a vida e o trabalho dos professores contribuirá para a construção da tão desejada mudança educativa, que não se dará sem a adesão livre, e por isso comprometida, desses mesmos professores. Dar-lhes voz ajudará na construção positiva da sua identidade e permitirá que se criem as condições para uma prática dialógica de construção curricular. 


\section{Referências}

BERGAMASCHI, Maria Aparecida; ALMEIDA, Dóris Bittencourt. Memoriais escolares e processos de iniciação à docência. Educação em revista, Belo Horizonte, v. 29, n. 2, p. 15-41, jun. 2013.

BARREIRO, Cristhianny Bento. Pesquisa-formação: a construção de si na escuta do outro. 2009. $130 \mathrm{f}$. Tese (Doutorado em Educação) Faculdade de Educação, Pontifícia Universidade Católica do Rio Grande do Sul, Porto Alegre, 2009.

BUENO, Belmira Oliveira et al. Histórias de vida e autobiografias na formação de professores e profissão docente (Brasil, 1985-2003). Educação e Pesquisa, São Paulo, v. 32, n. 2, p. 385-410, mai./ago. 2006.

CINTRA, Simone Cristiane Silveira; ALBANO, Ana Angélico. Memória e (re)criação na formação de professores: trilhando caminhos. Cadernos CEDES, v. 30, n. 80, p. 105-111, jan./abr. 2010.

COUTINHO, Clara. A qualidade da investigação educativa de natureza qualitativa: questões relativas à fidelidade e validade. Educação Unisinos, São Leopoldo, RS, v. 12, n. 1, p. 5-15, jan./abr. 2008.

DAY, Christopher. A paixão pelo ensino. Porto: Porto Editora, 2004. 272 p.

DOMINICE, Pierre. L'histoire de vie comme processus de formation. 1.ed. Paris: L'Harmattan, 1990. 174 p.

DUBAR, Claude. A socialização: construção das identidades sociais e profissionais. 1. ed. São Paulo: Martins Fontes, 2005. 343 p.

DUBAR, Claude ; TRIPIER, Pierre. Sociologie des professions. Paris : Armand Colin, collection «U», 1998, $251 \mathrm{p}$.

ESTRELA, Maria Teresa. Profissão docente: dimensões afetivas e éticas. 1. ed. Mangualde: Edições Pedago, 2004. $112 \mathrm{p}$.

ESTRELA, Maria Teresa. Velhas e novas profissionalidades, velhos e novos profissionalismos: tensões, paradoxos, progressos e retrocessos. Investigar em Educação - Revista da Sociedade Portuguesa de Ciências da Educação, Braga, v. 1, n. 2, p. 5-30, 2014.
FERnANDES, Natal Lânia Roque. Processos identitários docentes: percursos de vida e de trabalho no contexto do Proeja do Instituto Federal de Educação, Ciência e Tecnologia do Ceará. 2012. 174 f. Tese (Doutorado em Educação) - Faculdade de Educação, Universidade Federal do Ceará, Fortaleza, 2012.

GOODSON, Ivor. Narrativas em Educação: a vida e a voz dos professores. Porto: Porto Editora, 2015. 160 p.

GOODSON, Ivor. As políticas de currículo e de escolarização. Petropolis, RJ: Vozes, 2008. 168 p.

HARGREAVES, Andy. Four ages of professionalism and professional learning. Teachers and teaching: theory and practice, v. 6, n. 2, p. 151-182, jun. 2000.

HARGREAVES, Andy; FINK, Dean. Liderança sustentável. Porto: Porto Editora, 2007. 284 p.

HELMER, Ester Almeida. 0 processo de construção da profissionalidade docente no Instituto Federal de Educação, Ciência e Tecnologia de São Paulo. 2012. 261 f. Tese (Doutorado em Ciências Humanas) - Universidade Federal de São Carlos, São Carlos, 2012.

HERDEIRO, Rosalina. Identidade(s), carreira e desenvolvimento profissional: um estudo junto de professores do 1o CEB. 2012. $371 \mathrm{f}$. Tese (Doutorado em Ciências da Educação) - Instituto de EducaçãoFaculdade de..., Universidade do Minho, Braga, 2012. HUBERMAN Michaël, La vie des enseignants, évolution et bilan d'une profession, Neuchâtel, Suiça: Delachaux \& Niestlé, 1989. 340 p

JOSSO, Marie-Christine .Cheminer vers soi. Lausanne, Suiça: l'Age d'homme, 1991. 447 p.

JOSSO, Marie-Christine. História de vida e projeto : a história de vida como projeto e as "histórias de vida" a serviço de projetos Educação e Pesquisa. São Paulo, vol.25, no.2, p11-23, jul/dez, 1999.

KELCHTERMANS, G. O Comprometimento profissional para além do contrato: autocompreensão, vulnerabilidade e reflexão de professores. In: FLORES, M. A.; VEIGA, A. M. Veiga Simão, aprendizagem e desenvolvimento profissional de professores: contextos e perspetivas. Mangualde: Edições Pedago, 2009. p. 61-98. 
KROEFF, Maria Bernardete Moreira. Histórias de vida: trajetórias de professoras no cenário político de Porto Alegre - perfis (auto)biográficos no mundo contemporâneo. 2010. 163 f. Tese (Doutorado em Educação) - Faculdade de Educação Pontificia Universidade Católica do Rio Grande do Sul, Porto Alegre, 2010.

LIMA, Jorge; PACHECO, José Augusto. (Orgs.). Fazer investigação: contributos para a elaboração de dissertações e teses. Porto: Porto Editora. 160 p.

MATIZ, Luciana. A construção de identidades de professores do 3o CEB e do ensino secundário num contexto de mudança: um estudo narrativo com diferentes gerações de professores. 2013. 343 f. Tese (Doutorado em Educação) - Faculdade de Educação Universidade do Porto, Porto, 2013.

MORGADO, José Carlos. Processos e práticas de (re)construção da autonomia curricular. 2003. 365 f. Tese (Doutorado Ciências da Educação) - Instituto de Educação, Universidade do Minho, Braga, 2003.

MORGADO, José Carlos. Currículo, identidade e profissionalidade docente: desafios contemporâneos. In: MORGADO, José Carlos; QUITEMBO, Alberto Domingos AUTOR/ES. (Org./Orgs.). Currículo, avaliação e inovação em Angola: perspetivas e desafios. Benguela: Ondjiri Editores, 2014, p. 129-154.

NÓVOA, António. Os professores e a sua formação. Lisboa: Publicações Dom Quixote, 1992. 192 p.

NÓVOA, António. Vidas de professores. 2. ed. Porto: Porto Editora, 2013. 116 p.

OLIVEIRA, Hélia Margarida; CYRINO, Márcia Cristina de Costa Trindade. A formação inicial de professores de matemática em Portugal e no Brasil: narrativas de vulnerabilidade e agência. Interacções, Santarém, v. 7, n. 18, p. 104-130, 2011.

OSBORN, Marilyn. Changing the context of teachers' work and professional development: a European perspective. International journal of educational research, v. 45, n. 4, p. 242-253, 2006.

PACHECO, José Augusto. Políticas educativas e curriculares: para uma análise do contexto português.
In: CONGRESSO DA SPCE, Educação para o sucesso: políticas e atores, IX., 2008 Funchal. Anais: Universidade da Madeira, 2008. p. 159-168.

PACHECO, José Augusto. Processos e práticas de educação e formação: Para uma análise da realidade portuguesa em contextos de globalização. Revista Portuguesa de Educação, Braga, v. 22, n. 1, p. 105-143, 2009.

PASSEGGI, Maria da Conceição; SOUZA, Elizeu Clementino de.; VICENTINI, Paula Perin. Entre a vida e a formação: pesquisa (auto)biográfica, docência e profissionalização. Educação em Revista, v. 27, n. 1, p. 369-386, abr. 2011.

PEREIRA, Gilson de Almeida. No fio da história: uma análise da (re)construção identitária dos professores: entrecruzando tempos, memórias e espaços. 2007. 164 f. Tese (Doutorado em Educação) - Faculdade de Educação, Pontifícia Universidade Católica do Rio Grande do Sul, Porto Alegre, 2007.

PINHO, Ana Sofia Reis de Castro e. Intercompreensão, identidade e conhecimento profissional na formação de professores de línguas. 2008. $315 \mathrm{f}$. Tese (Doutorado em Educação) - Faculdade de Educação, Universidade de Aveiro, Aveiro, 2008.

RODRIGUES, Elsa Maria Pereira. As políticas educativas e o impacto no trabalho dos professores. 2012. 423 f. Tese (Doutorado em Ciências da Educação) - Faculdade de Educação, Universidade de Aveiro, Aveiro, 2012.

ROLDÃO, Maria do Céu. Profissionalidade docente em análise-especificidades dos ensinos superior e não superior. Nuances: estudos sobre educação, São Paulo, v. 12, n. 13, p. 105-126, jan./dez. 2005.

SACHS, Judith. The activist teaching profession. Buckigham: Open Unversity Press, 2003. 165 p.

SOUZA, Elizeu Clementino. (Org.). Autobiografias, histórias de vida e formação: pesquisa e ensino. Porto Alegre: EDPUCRS; Salvador: EDUNEB, 2006. 372 p.

TERREMOTO, Maria Leonor Alexandre Borges Santos. Da prática à praxis: os saberes experienciais dos professores na construção do ser professor do 1o ciclo do ensino básico. 2012. 443 f. Tese (Douto- 
rado em Educação) - Instituto de Educação, Universidade de Lisboa, Lisboa, 2012.

XAVIER, Libânia Nacif. A construção social e histórica da profissão docente uma síntese necessária.
Revista Brasileira de Educação, Rio de Janeiro, v. 19, n. 59, p. 827-849, out./dez. 2014.

Recebido em: 10.01.2016

Aprovado em: 12.03 .2016

Raquel Sofia dos Santos Macedo Matos é licenciada em Línguas e Literaturas Modernas - variante de Estudos Portugueses, pela Universidade do Porto. Tem pós-graduação em Desenvolvimento Curricular e Inovação Educativa, pela Universidade do Minho, e é doutoranda em Ciências da Educação, ramo de Desenvolvimento Curricular, na mesma universidade. Leciona a disciplina de Português no Ensino Básico. Foi docente da disciplina Portuguese as a Foreign Language, na Universidade Católica do Porto e Formadora de Cursos de Educação e Formação de Adultos (EFA), organizados pelo Ministério da Educação português. E-mail: id6255@alunos.uminho.pt | raquelsmatos@gmail.com

Rua Germão Galharde, no 4, 5o drt. 4715-290 - Braga, Portugal. 